\title{
Temperature trends at the Mauna Loa observatory, Hawaii
}

\author{
B. D. Malamud ${ }^{1}$, D. L. Turcotte ${ }^{2}$, and C. S. B. Grimmond ${ }^{1}$ \\ ${ }^{1}$ King's College London, Department of Geography, Strand, London, WC2R 2LS, UK \\ ${ }^{2}$ University of California, Department of Geology, Davis, CA 95616, USA
}

Received: 13 August 2010 - Published in Clim. Past Discuss.: 7 September 2010

Revised: 13 July 2011 - Accepted: 4 August 2011 - Published: 31 August 2011

\begin{abstract}
Observations at the Mauna Loa Observatory, Hawaii, established the systematic increase of anthropogenic $\mathrm{CO}_{2}$ in the atmosphere. For the same reasons that this site provides excellent globally averaged $\mathrm{CO}_{2}$ data, it may provide temperature data with global significance. Here, we examine hourly temperature records, averaged annually for 1977-2006, to determine linear trends as a function of time of day. For night-time data (22:00 to 06:00 LST (local standard time)) there is a near-uniform warming of $0.040^{\circ} \mathrm{C} \mathrm{yr}^{-1}$. During the day, the linear trend shows a slight cooling of $-0.014{ }^{\circ} \mathrm{C} \mathrm{yr}^{-1}$ at 12:00 LST (noon). Overall, at Mauna Loa Observatory, there is a mean warming trend of $0.021^{\circ} \mathrm{C} \mathrm{yr}^{-1}$. The dominance of night-time warming results in a relatively large annual decrease in the diurnal temperature range (DTR) of $-0.050^{\circ} \mathrm{C} \mathrm{yr}^{-1}$ over the period 1977 2006. These trends are consistent with the observed increases in the concentrations of $\mathrm{CO}_{2}$ and its role as a greenhouse gas (demonstrated here by first-order radiative forcing calculations), and indicate the possible relevance of the Mauna Loa temperature measurements to global warming.
\end{abstract}

\section{Introduction}

The observations since 1958 that established the systematic increase of atmospheric $\mathrm{CO}_{2}$ (Keeling et al., 1976) were carried out at the NOAA Observatory on Mauna Loa (altitude $3397 \mathrm{~m}$ a.s.l. (above sea level)), Big Island, Hawaii. It has been argued (Ryan, 2001) that this is an excellent location to make atmospheric measurements because of the isolation from localized anthropogenic and continental sources and sinks. The well-mixed atmosphere at this isolated highelevation observatory has very small variations in $\mathrm{CO}_{2}$ con-

Correspondence to: B. D. Malamud (bruce.malamud@kcl.ac.uk) centrations, and the observations have been widely taken as representative of global average values (IPCC, 2007). We suggest that this single high-altitude NOAA station at Mauna Loa Observatory provides a background site for temperature which may be of similar global significance as the $\mathrm{CO}_{2}$ data obtained there. We note however, that unlike $\mathrm{CO}_{2}$, there is considerably more spatial variability amongst temperature trends. While there is a general trend of global warming, there are large variations in temperature trends in various parts of the world and in some regions there is cooling. We use the high-quality hourly temperature data (NOAA, 2009) from this observatory for the time period 1977-2006 to study (a) trends in annual mean temperature data as a function of the hour of the day, and (b) trends in annual mean diurnal temperature ranges (DTR), where the DTR is the difference between the maximum and minimum temperatures in a given $24 \mathrm{~h}$ period.

We recognize that temperature trends are often obtained utilizing spatial averages of results from multiple stations, rather than one station. For example, Jones and Moberg (2003) utilized 5159 stations to map global values of surface temperature trends. In another example, trends for averaged stations in the Hawaiian Islands have been given by Giambelluca et al. (2008). However, we propose that using high-quality hourly temperature data obtained from this high-altitude NOAA tropical site, might be consistent with globally averaged temperature trends.

First, the 30-yr Mauna Loa NOAA observatory temperature hourly data used, including missing observations, are described (Sect. 2). Then, temperature trends for the period of study as a function of time of day are given and a mean rate of temperature warming is determined (Sect. 3). This value is compared to IPCC (2007) global temperature trends and warming rates inferred from changes in global $\mathrm{CO}_{2}$ concentrations. Next, the trend in DTR at this observatory is derived and compared with other studies (Sect. 4). Finally, the implications of our results are discussed (Sect. 5). 


\section{Mauna Loa temperature data}

The Mauna Loa Observatory hourly mean air temperature measurements used here are from the NOAA Earth System Research Laboratory (ESRL) station 31 (altitude 3397 ma.s.l., $19.54^{\circ} \mathrm{N}, 155.58^{\circ} \mathrm{W}$ ) and are measured in an aspirated radiation shield at $2 \mathrm{~m}$ above ground (NOAA, 2009). During the 30-yr period, 1 January 1997 to 31 December 2006, three different systems were used to collect temperature data (T. Mefford, Global Monitoring Division, NOAA, personal communication, 2009): (a) January 1977-December 1983: Thermistor; (b) January 1984October 1993: linearized thermistors; (c) October 1993December 2006: hygro-thermometer. Hourly data were based on the mean of one minute samples from October 1993 to December 2006; previous to 1993, longer time periods were averaged.

Prior to analysis, seven leap days were removed and missing hourly data were gap-filled. For the period of record, 1 January 1977-31 December 2006, there were $n=262968$ hourly measurements, of which 9695 values $(3.7 \%)$ were missing. Missing values were found to be approximately uniformly distributed by year and also as a function of the hour of day. Interpolation to replace missing data was done as follows: (a) if data for the missing hour were available for that same hour within 7 days on both sides, these two values were averaged; (b) if data as described in "a" were not available, values were substituted from the subsequent year for the same hour and day. The two types of interpolation accounted for about $50 \%$ each in terms of missing values. The longest gaps were 29 March-28 April 1984 and 14 August-15 September 1997; the first gap was caused by a volcanic eruption at Mauna Loa which severed power lines to the observatory and the second gap was caused by a major lightning strike which affected all projects at the observatory (T. Mefford, Global Monitoring Division, NOAA, personal communication, 2009).

\section{Temperature trends}

Our first objective is to determine, as a function of each hour of the day $(h)$, the linear trends of the Mauna Loa temperature data over the $30 \mathrm{yr}$ of record, 1 January 1977 to 31 December 2006. We illustrate our data analyses using hourly temperatures $T$ measured at $h=12: 00 \mathrm{LST}$ (noon) and 24:00 LST (midnight). In Fig. 1, we show the daily temperatures for the period of record at these times of day. Also shown are the annual means of the daily values and the best-fit linear trend (using ordinary least-squares) to the annual values. The slope of the annual trend line for 12:00 LST has a small rate of annual cooling, $\mathrm{d} T / \mathrm{d} t=-0.014 \pm 0.014{ }^{\circ} \mathrm{C} \mathrm{yr}^{-1}$ (uncertainties are \pm 1 s.e. (standard error) of the slope). The slope of the annual trend line for 24:00 LST has a modest rate of annual
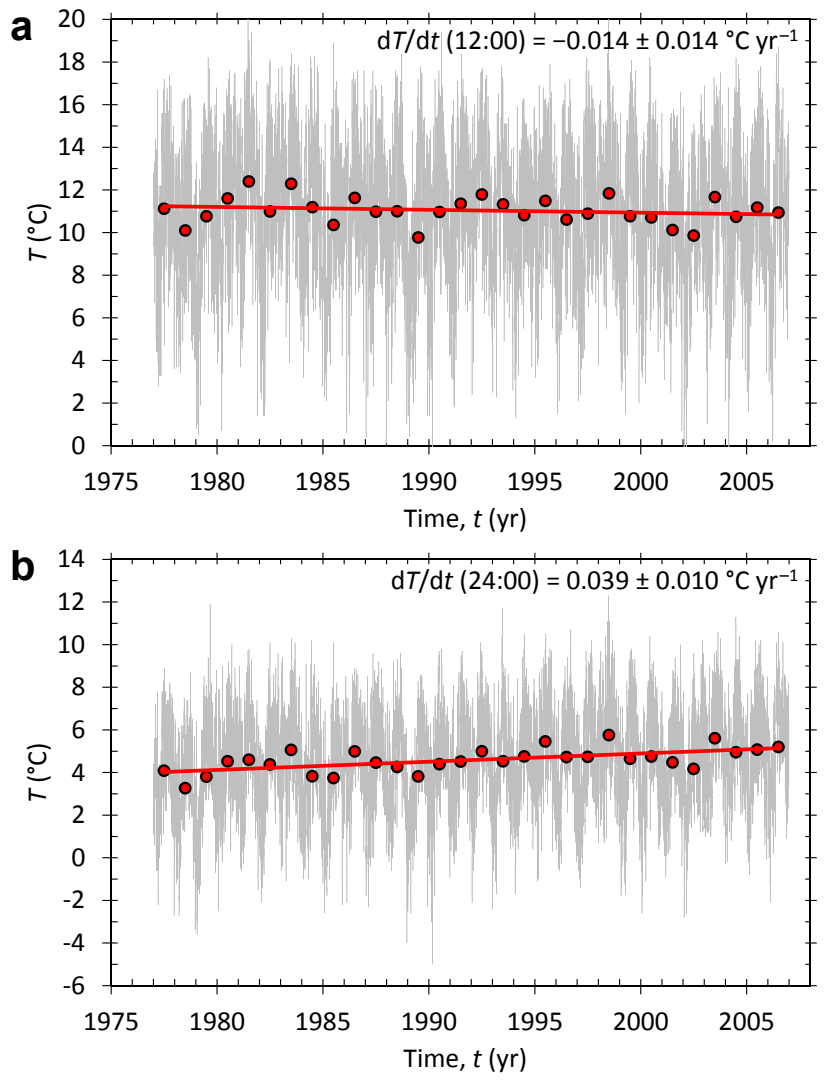

Fig. 1. Temperatures at (a) 12:00 LST (noon) and (b) 24:00 LST (midnight) at the Mauna Loa Observatory, Hawaii, 1977-2006, based on hourly temperature data from NOAA (2009). Shown are the 30-yr daily sequence of noon and midnight temperatures $T$ (light grey lines) as a function of time $t$ from 1 January 1977 to 31 December 2006. Also shown (circles) are the annual means of these daily values. The best-fit line using ordinary least-squares is shown for both times (thick solid line), with slopes $\mathrm{d} T / \mathrm{d} t(12: 00)=-0.014 \pm 0.014{ }^{\circ} \mathrm{C} \mathrm{yr}^{-1}$ and $\mathrm{d} T / \mathrm{d} t(24: 00)=-0.039 \pm 0.010^{\circ} \mathrm{C} \mathrm{yr}^{-1}$ (uncertainties \pm 1 s.e. of the slope).

warming, $\left(\mathrm{d} T / \mathrm{d} t=0.039 \pm 0.010^{\circ} \mathrm{C} \mathrm{yr}^{-1}\right)$. Fitting a single linear trend to the $30 \mathrm{yr}$ of data can be questioned because of their relatively large scatter; this is addressed in Sect. 4. In addition to scatter, another source of variability is large scale synoptic influences (Giambelluca et al., 2008) such as the Pacific Decadal Oscillation (PDO). We emphasise linear temperature trends in our analyses, so as to compare them with the linear trend in global $\mathrm{CO}_{2}$ concentrations at the same site.

The dependence of $T$, the mean of all hourly temperatures at a specified time of day, $h$, as a function of $h$, is given for the entire period (1977-2006) in Fig. 2a. Values for $T$ range from a maximum $T=11.0 \pm 3.0^{\circ} \mathrm{C}$ at $h=12: 00$ LST (uncertainties are \pm s.d. (standard deviation) of the daily values given in Fig. 1) to a minimum $T=3.7 \pm 2.2^{\circ} \mathrm{C}$ at $h=05: 00 \mathrm{LST}$ (Fig. 2a). The dependence 
of the linear temperature trends for the entire period, $\mathrm{d} T / \mathrm{d} t$, as a function of the time of day, $h$, have values that range from a warming trend $\mathrm{d} T / \mathrm{d} t=0.040 \pm 0.009^{\circ} \mathrm{C} \mathrm{yr}^{-1}$ ( \pm 1 s.e. of the slope) at $h=02: 00 \mathrm{LST}$ to a slight cooling trend $\mathrm{d} T / \mathrm{d} t=-0.014 \pm 0.014{ }^{\circ} \mathrm{C} \mathrm{yr}^{-1}$ at $h=12: 00 \mathrm{LST}$ (i.e., the slope of the trend given in Fig. 1a) (Fig. 2b). This type of hour of day variability of $\mathrm{d} T / \mathrm{d} t$ has been considered previously for urban data in Japan (Fujibe, 2009).

The difference between the maximum and minimum $\mathrm{d} T / \mathrm{d} t$ in Fig. $2 \mathrm{~b}$ is $0.054{ }^{\circ} \mathrm{Cyr}^{-1}$. At night (22:00 to 06:00 LST) there is a near uniform heating trend with values

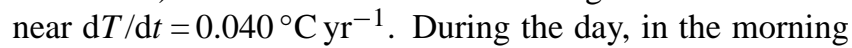
there is a reduction in the annual warming rate, with a localized minimum (and overall cooling per year) at 12:00 LST of $\mathrm{d} T / \mathrm{d} t=-0.014{ }^{\circ} \mathrm{C} \mathrm{yr}^{-1}$, and then an increase again of the warming trend during the afternoon. It is interesting to note the reflection symmetry about a horizontal line between the shapes of the diurnal variability of the mean temperature (Fig. 2a) and the temperature trends (Fig. 2b) as a function of hour of day. Annual warming over the period of record in Fig. $2 \mathrm{~b}$ corresponds to low temperatures in Fig. 2a, and relative annual cooling in Fig. 2b to high temperatures in Fig. 2a.

We next consider whether the hourly values of the annual temperature trends $(\mathrm{d} T / \mathrm{d} t)$ over the $30 \mathrm{yr}$ of record have seasonal variability. In Fig. 3a we present temperature trends as a function of hour of day on a seasonal basis, with the four seasons defined as: spring (March, April, May), summer (June, July, August), fall (September, October, November), and winter (December, January, February). Winter includes January and February from year $t$ and December from year $t-1$. Also included in Fig. $3 a$ are the annual mean values from Fig. 2b ("all months"). From Fig. 3a we observe that the seasonal variability at a given hour is on average only about $25 \%$ of the overall daily variability, with the dependence of temperature trends on time of day very similar, in terms of the overall shape of the five curves. The rates of warming are highest in the spring and lowest in the fall and winter. Comparing the mean annual warming (cooling) rates of $\mathrm{d} T / \mathrm{d} t$ as a function of hour of day for "all months" to each season, spring values of $\mathrm{d} T / \mathrm{d} t$ are overall higher, summer values very similar, winter values lower, and fall values mostly lower, except for 07:00-10:00 LST when they are higher.

In order to further quantify for 1977-2006 the seasonal effects on annual mean warming (cooling) as a function of time of day, we give the number of hours per day that the temperature trends have a specified range of annual warming or cooling values. We illustrate our approach in Fig. 3b for spring (March, April, May) finding there are $1.8+2.4=4.2 \mathrm{~h}$ (out of $24 \mathrm{~h}$ ) that the temperature trend is within the range $0.00 \leq \mathrm{d} T / \mathrm{d} t<0.01^{\circ} \mathrm{C} \mathrm{yr}^{-1}$, i.e. for spring during the 30yr period 1977-2006, $18 \%$ of the hours during each calendar day, on average, have zero to slight warming trends. In Fig. $3 c$ we present the number of hours per day with $\mathrm{d} T / \mathrm{d} t$ in a given temperature trend range (over $30 \mathrm{yr}$ ), cool-
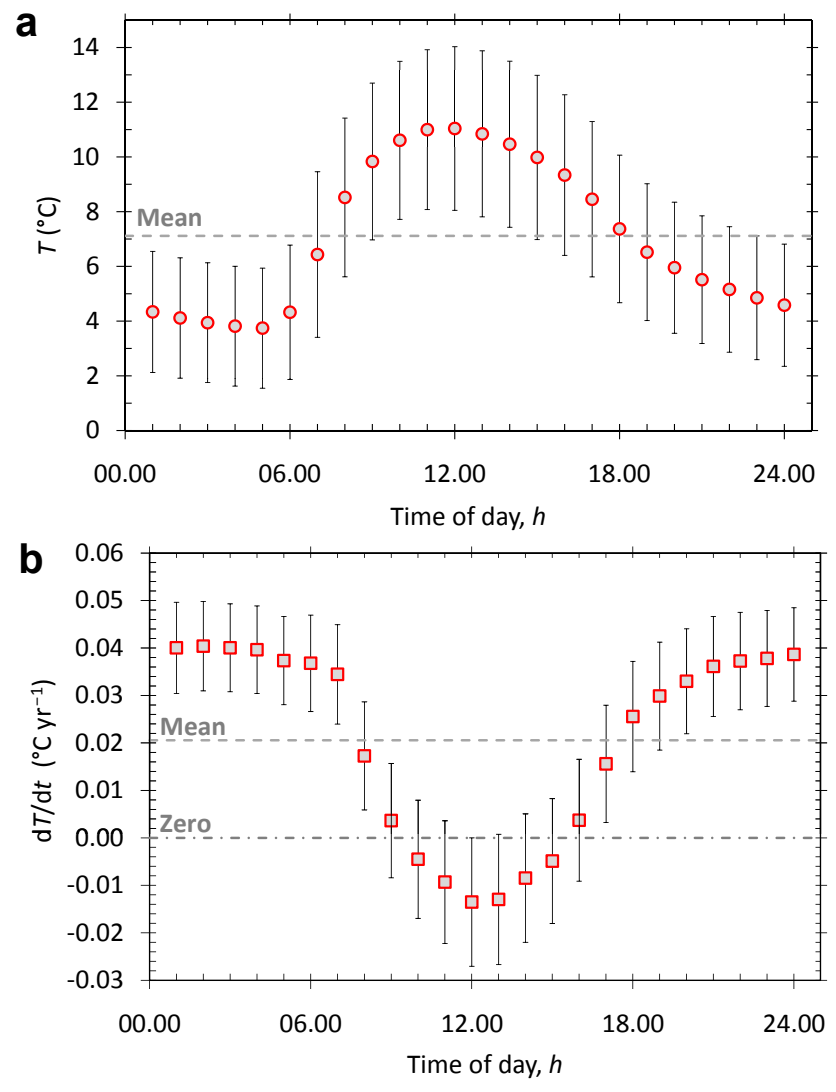

Fig. 2. Mean temperatures and best-fit trend-line slopes for the 30yr Mauna Loa Observatory, Hawaii data (NOAA, 2009), as a function of time of day (LST). (a) The mean of all hourly temperatures, $T$, at a specified time of day, $h$, for 1977-2006 (circles) with error bars \pm 1 s.d. of hourly values at time $h$ for this period. The mean of the time-of-day values is $T=7.11^{\circ} \mathrm{C}$ (dashed line). (b) Annual mean rates of warming (cooling) $\mathrm{d} T / \mathrm{d} t$ (squares) are given as a function of time of day, $h$ (error bars \pm 1 s.e. of the slope). The values at 12:00 LST and 24:00 LST are the slopes of the trend lines given in Fig. 1. The mean rate of warming (upper dashed line) for all hours is $\mathrm{d} T / \mathrm{d} t=0.021 \pm 0.011^{\circ} \mathrm{C} \mathrm{yr}^{-1}$ ( \pm mean of error bars in Fig. 2b).

ing (dark blue to light blue over three trend ranges) to warming (light red to dark red, five trend ranges), as a function of four seasons and "all months". Darker colours indicate larger amounts of cooling (blue) or warming (red) over the 30 -yr record. Summer and "all months" are very similar in the distribution of hours amongst the different trend ranges, with $17.7-17.9 \mathrm{~h}$ warming, on average out of the $24 \mathrm{~h}$ (74$75 \%$ of the time), and $6.1-6.3 \mathrm{~h}$ ( $25-26 \%$ of the time) cooling. Spring has the largest amount of warming, $21.2 \mathrm{~h}(88 \%$ of the time), and winter the largest amount of cooling, 7.7 h (32\% of the time). Fall, although similar to summer/all months, in total number of hours of warming vs. cooling, is the only season to have temperature trends over the 30yr record that go across all ranges of cooling and warming presented in Fig. 3c. 

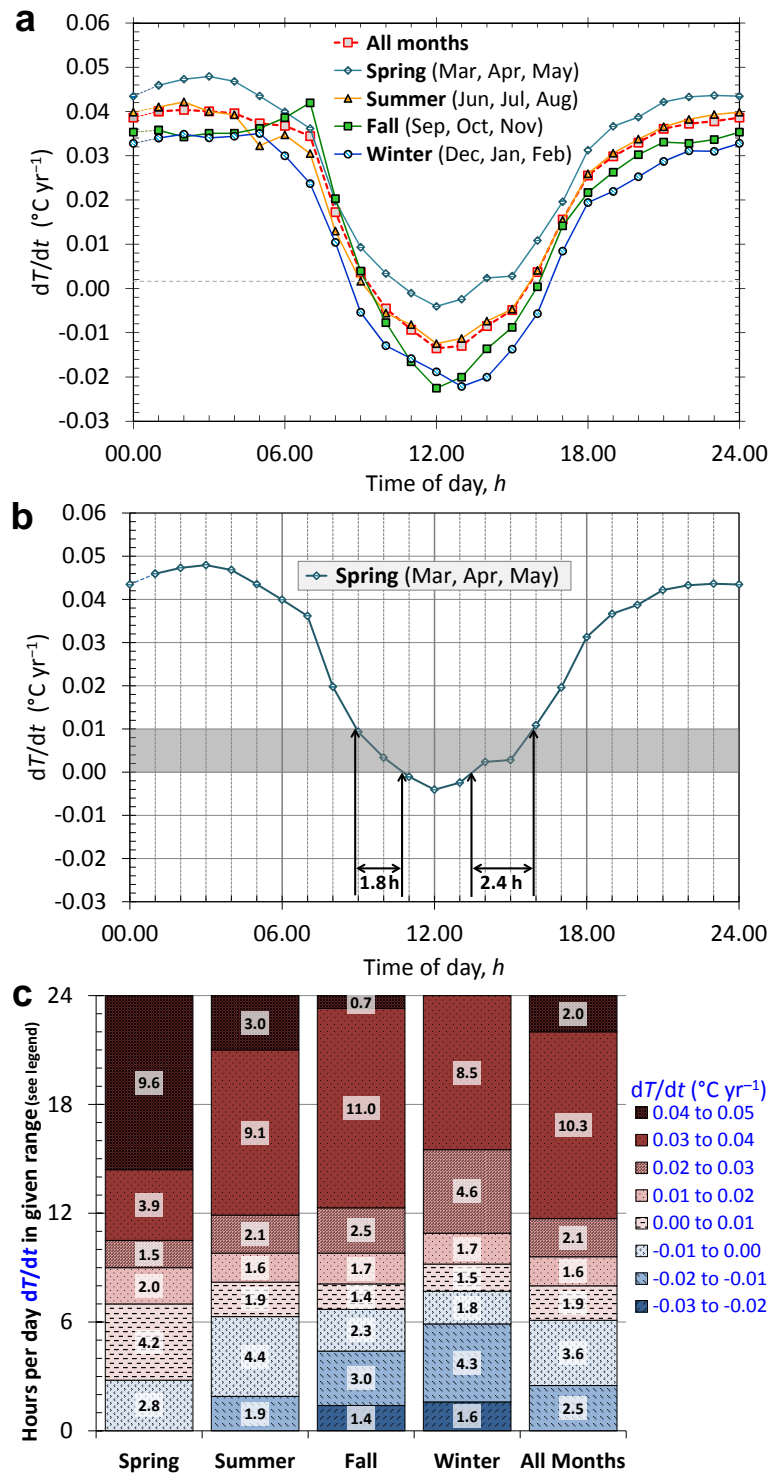

Fig. 3. Best-fit trend-line slopes, $\mathrm{d} T / \mathrm{d} t$, for the 30-yr Mauna Loa Observatory, Hawaii data (NOAA, 2009), as a function of time of day, $h$, for each season and all months together: (a) Annual mean rates of warming (cooling) $\mathrm{d} T / \mathrm{d} t$ for 1977-2006 are given for "all months" (large squares, same as Fig. 2b), and the four seasons: spring (diamonds; March, April, May), summer (triangles; June, July, August), fall (small squares; September, October, November), winter (circles; December, January, February). The mean rates of warming for the four seasons are: $\mathrm{d} T / \mathrm{d} t=0.027 \pm 0.019^{\circ} \mathrm{C} \mathrm{rr}^{-1}$ (spring), $\mathrm{d} T / \mathrm{d} t=0.020 \pm 0.012{ }^{\circ} \mathrm{C} \mathrm{yr}^{-1} \quad$ (summer), $\mathrm{d} T / \mathrm{d} t=0.018 \pm 0.011$ ${ }^{\circ} \mathrm{C} \mathrm{yr}^{-1}$ (fall), and $\mathrm{d} T / \mathrm{d} t=0.013 \pm 0.022{ }^{\circ} \mathrm{C} \mathrm{yr}^{-1}$ (winter), with uncertainties \pm mean of the s.e. on slopes for each hour. (b) Example of calculating the mean number of hours per day that $\mathrm{d} T / \mathrm{d} t$ are in a given range of warming (cooling), here done for $0.00 \leq \mathrm{d} T / \mathrm{d} t<0.01{ }^{\circ} \mathrm{C} \mathrm{yr}^{-1}$ and spring, i.e. $4.2 \mathrm{~h}$. (c) Number of hours per day that overall temperature trends, $\mathrm{d} T / \mathrm{d} t$, at Mauna Loa over the 30-yr period, is in a given "range" (see legend) going from "cooling" (blue) to warming (pink/red), for each of the four seasons and "all months".

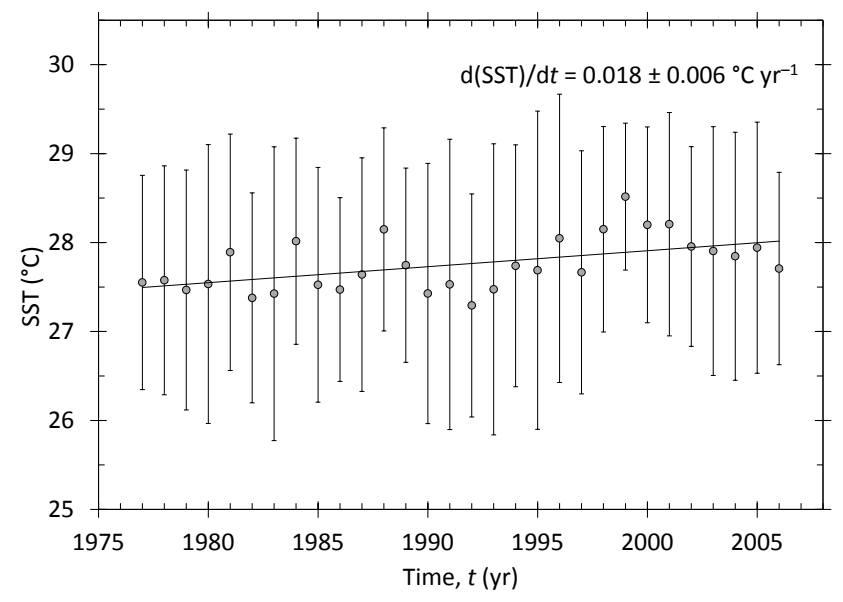

Fig. 4. NCEP monthly reanalysis data (Kalnay et al., 1996; NOAA, 2010) for Sea Surface Temperature (SST) for the region surrounding Mauna Loa, $18.1-21.9^{\circ} \mathrm{N}$ and $153.8-157.5^{\circ} \mathrm{W}, 1977-2006$. Circles represent the mean of the monthly SST values for a given year, with error bars \pm 1 standard deviation of the 12 monthly SST values. The best-fit line using ordinary least-squares is shown (solid line), with slope $\mathrm{d}(\mathrm{SST}) / \mathrm{d} t=0.018 \pm 0.006^{\circ} \mathrm{C} \mathrm{yr}^{-1}$ (uncertainties \pm 1 s.e. of the slope).

The mean of the Mauna Loa Observatory annual warming and cooling trends given in Fig. $2 b$ gives an overall warming trend (dashed horizontal line) of $\mathrm{d} T / \mathrm{d} t=0.021 \pm 0.011^{\circ} \mathrm{C} \mathrm{yr}^{-1} \quad( \pm$ mean of error bars in Fig. 2b). Giambelluca et al. (2008) obtained a mean rate of warming for 1975-2006 averaged over four Hawaii stations with elevations $916-3140 \mathrm{~m}$ a.s.l. of $\mathrm{d} T / \mathrm{d} t=0.027^{\circ} \mathrm{C} \mathrm{yr}^{-1}$, which is consistent with our Mauna Loa mean warming trend results, within the error bars.

Further to our Mauna Loa single instrument station (micro-climate) analysis, regional analysis is performed using NCEP (National Climate Environmental prediction) monthly reanalysis data (Kalnay et al., 1996; NOAA, 2010). Sea Surface Temperatures (SST) for the region $18.1-21.9^{\circ} \mathrm{N}$ and $153.8-157.5^{\circ} \mathrm{W}$ for the period $1977-2006$ were analysed. This $3.8^{\circ} \times 3.7^{\circ}$ region contains the Mauna Loa Observatory (MLO) site in Hawaii, and reflects the temporal pattern of SST in the region of Hawaii. The resultant trend (Fig. 4) of SST as a function of year, gives a gradient over the $30 \mathrm{yr}$ period of $\mathrm{d}(\mathrm{SST}) / \mathrm{d} t=0.018 \pm 0.006^{\circ} \mathrm{C} \mathrm{yr}^{-1}$ ( \pm 1 s.e. of slope), consistent with our Mauna Loa mean warming trend results, $\mathrm{d} T / \mathrm{d} t=0.021 \pm 0.011^{\circ} \mathrm{C} \mathrm{yr}^{-1}$.

We now move from the local (micro-climate) and regional trends, to global trends. The mean rate of warming inferred from averaged annual global surface temperature measurements, 1980-2005, by the IPCC (2007) is $\overline{\mathrm{d} T / \mathrm{d} t}=0.018 \pm 0.005^{\circ} \mathrm{Cyr}^{-1}$. We note the consistency of the regional and global temperature trend values. Both of these are also consistent with our local value at Mauna Loa. One interpretation of these similarities is that the Mauna Loa 
Observatory value is representative of the mean rate of global warming. This is in direct analogy to the widely accepted association of the mean rate of increase in the concentration of $\mathrm{CO}_{2}, \mathrm{~d} C / \mathrm{d} t=1.6 \mathrm{ppmv} \mathrm{yr}^{-1}$ (ppm by volume per year) measured at the observatory (CDIAC, 2009) over the same period, with the rate of increase of $\mathrm{CO}_{2}$ globally. An alternative interpretation is that the regional SST trend is influencing the local Mauna Loa Observatory temperature trend.

Examination of the theoretical relation between changes in global mean atmospheric $\mathrm{CO}_{2}$ concentrations and changes in global mean atmospheric temperatures relate to the change in radiative forcing $\Delta F$ (Myhre et al., 1998)

$\Delta F=5.35 \ln \left(\frac{C}{C_{0}}\right)$

with $\Delta F$ in $\mathrm{W} \mathrm{m}^{-2}, C$ the concentration of $\mathrm{CO}_{2}$ in ppmv, and $C_{0}$ a reference concentration for $\mathrm{CO}_{2}$. Based on annual mean $\mathrm{CO}_{2}$ observations at the Mauna Loa Observatory (CDIAC, 2009), we take $C_{0}=334 \mathrm{ppmv}$ for 1977 , and $C=382 \mathrm{ppmv}$ for 2006. Substitution of these values into Eq. (1) gives $\Delta F=0.72 \mathrm{~W} \mathrm{~m}^{-2}$. The change in mean atmospheric temperature $\Delta T$ is related to the change in radiative forcing $\Delta F$ by (IPCC, 2007)

$\Delta T=\lambda \Delta F$,

where $\lambda$ is the equilibrium climate sensitivity. Studies (Gregory et al., 2002; IPCC, 2007) give a preferred value $\lambda=0.8$ [0.5 to 1.2$]^{\circ} \mathrm{C} \mathrm{m}^{2} \mathrm{~W}^{-1}$. Substituting these values of $\lambda$ and $\Delta F=0.72 \mathrm{~W} \mathrm{~m}^{-2}$ into Eq. (2), gives $\Delta T=0.58$ [0.36 to $0.86]^{\circ} \mathrm{C}$ for the $30-\mathrm{yr}$ period $1977-2006$ or $\mathrm{d} T / \mathrm{d} t=0.019$ [0.012 to 0.029$]^{\circ} \mathrm{C} \mathrm{yr}^{-1}$, very similar to the mean rate of warming results we obtain for the Mauna Loa Observatory (Fig. 2b), $\mathrm{d} T / \mathrm{d} t=0.021 \pm 0.011^{\circ} \mathrm{C} \mathrm{yr}^{-1}$. Combining Eqs. (1) and (2) gives:

$T=5.35 \lambda \ln \left(\frac{C}{C_{0}}\right)+T_{0}$,

with $T$ in ${ }^{\circ} \mathrm{C}, \lambda$ in ${ }^{\circ} \mathrm{Cm}^{2} \mathrm{~W}^{-1}$, and $T_{0}$ a reference temperature. At the end of Sect. 4, this equation will be used to further explore the association between temperatures and $\mathrm{CO}_{2}$ concentrations at the Mauna Loa Observatory.

\section{Diurnal Temperature Range (DTR)}

To obtain the trend of the annual mean values of DTR at the Mauna Loa Observatory for 1977-2006, we first obtain the maximum and minimum hourly temperatures, for each $24 \mathrm{~h}$ period, $h=01: 00$ to 24:00 LST. The mean of these values over each calendar year gives the annual mean maximum, $T_{\max }$, and annual mean minimum, $T_{\min }$, temperatures (Fig. 5a). The best-fit linear slope (using ordinary least-squares) for the annual $T_{\max }$ data for 1977-2006 is $\mathrm{d} T_{\max } / \mathrm{d} t=-0.011 \pm 0.013^{\circ} \mathrm{C} \mathrm{yr}^{-1}( \pm 1$ s.e. of the slope $)$,
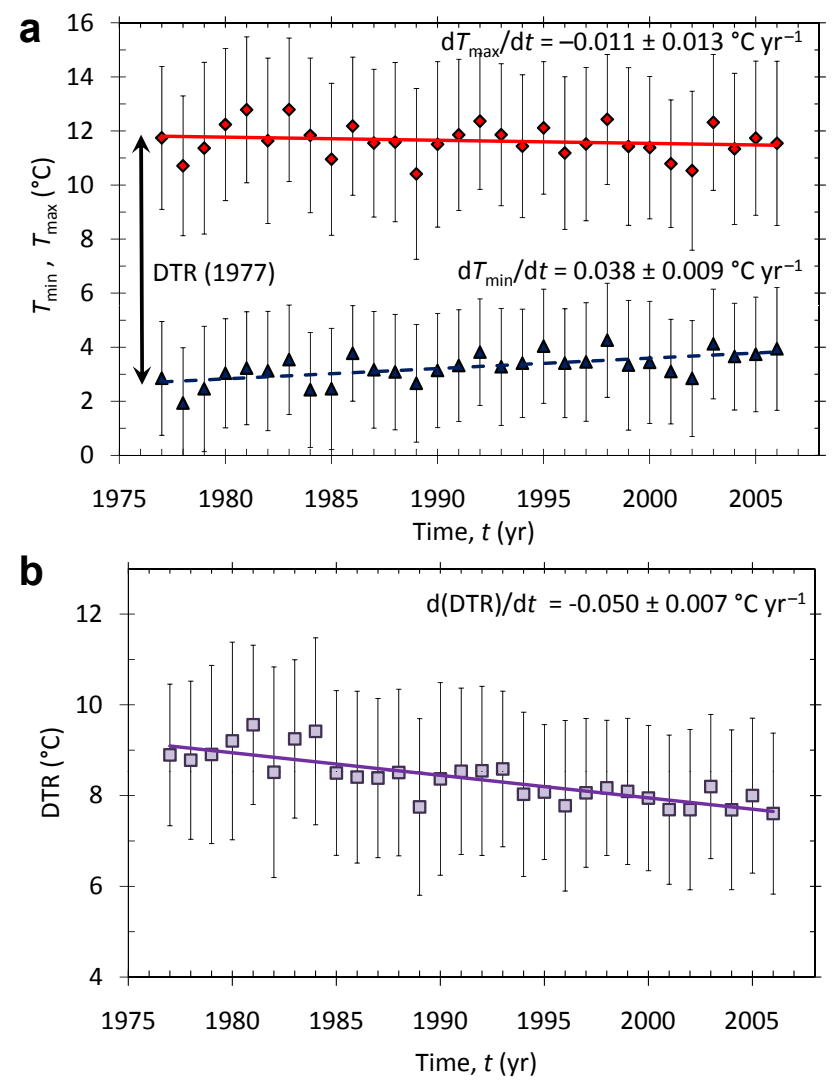

Fig. 5. Annual mean maximum temperatures $\left(T_{\max }\right)$, minimum temperatures $\left(T_{\min }\right)$, and diurnal temperature ranges (DTR), for 1977-2006, based on hourly Mauna Loa Observatory, Hawaii data (NOAA, 2009). (a) The sequence of annual mean maximum temperatures $T_{\max }$ (diamonds) and minimum temperatures $T_{\min }$ (triangles) are given as a function of time $t$ for 1977-2006 (error bars \pm 1 s.d. of daily values for that year). The best-fit linear trends (solid and dashed lines) of the annual values are shown along with their slopes ( \pm 1 s.e. of the slope). An illustration of $\mathrm{DTR}=T_{\max }-T_{\min }$ for 1977 is also shown (vertical arrow). (b) The annual mean values of DTR (squares) are given as a function of time $t$ ( \pm 1 s.d. of DTR values for that year). The best-fit linear trend (solid line) of the annual values is shown along with its slope ( \pm 1 s.e. of the slope).

which is, as expected, close to the 30-yr cooling trend of $\mathrm{d} T / \mathrm{d} t=-0.014 \pm 0.014{ }^{\circ} \mathrm{C} \mathrm{yr}^{-1}$ given in Figs. $1 \mathrm{a}$ and $2 \mathrm{~b}$ for 12:00 LST (noon). The best-fit linear trend for the minimum temperature is $\mathrm{d} T_{\min } / \mathrm{d} t=0.038 \pm 0.009^{\circ} \mathrm{C} \mathrm{yr}^{-1}$, which is close to the 24:00 LST (midnight) night-time warming trend given in Fig. $1 \mathrm{~b}$ and the overall night-time warming trends given in Fig. $2 b$.

The difference between the annual mean maximum and annual mean minimum temperatures is the annual mean DTR (illustrated for 1977 in Fig. 5a); this is equivalent to taking the mean of the daily DTR values for the year. The annual mean values of DTR are given in Fig. $5 \mathrm{~b}$ as a function of time $t$, for the period 1977-2006 at the Mauna 
Table 1. Diurnal temperate range (DTR) studies compared [m a.s.1. = metres above sea level].

\begin{tabular}{llllrl}
\hline Source & Location & Time Period & $\begin{array}{l}\text { Elevation } \\
(\mathrm{m} \text { a.s.l. })\end{array}$ & $\begin{array}{r}\text { Number of } \\
\text { stations }\end{array}$ & $\begin{array}{l}\mathrm{d}(\mathrm{DTR}) / \mathrm{d} t \\
\left({ }^{\circ} \mathrm{C} \mathrm{yr}^{-1}\right)\end{array}$ \\
\hline Giambelluca et al. (2008) & Hawaii & $1975-2006$ & $3-768$ & 17 & -0.012 \\
& & & $916-3400$ & 4 & -0.036 \\
Grant et al. (2005) & Mt Washington, & $1935-2003$ & 1914 & 1 & -0.0020 \\
& New Hampshire & & & & \\
This study & Mauna Loa, Hawaii & $1977-2006$ & 3397 & 1 & -0.050 \\
Vose et al. (2005) & Global & $1979-2004^{*}$ & Variable & 6970 & -0.0001 \\
\hline
\end{tabular}

* Individual stations had at least $20 \mathrm{yr}$ of data.

Loa Observatory. The best-fit trend using ordinary leastsquares is $\mathrm{d}(\mathrm{DTR}) / \mathrm{d} t=-0.050 \pm 0.007^{\circ} \mathrm{C} \mathrm{yr}^{-1}( \pm 1$ s.e. of the slope). This absolute value of $\mathrm{d}(\mathrm{DTR}) / \mathrm{d} t$ is very close to the difference between the maximum and minimum $\mathrm{d} T / \mathrm{d} t$ annual trends $\left(0.054^{\circ} \mathrm{C} \mathrm{yr}^{-1}\right)$ given in Fig. $2 \mathrm{~b}$ as a function of hour of the day.

The application of a single trend line to the $30 \mathrm{yr}$ of data at the Mauna Loa Observatory can certainly be questioned because of the relatively large scatter of the annual data. To partially address this question, we divided the annual DTR data (presented in Fig. 5b) into two 15-yr periods and obtained the best-fit trends using ordinary least-squares. For 1977-1991, we obtain $\mathrm{d}(\mathrm{DTR}) / \mathrm{d} t=-0.064 \pm 0.021^{\circ} \mathrm{C} \mathrm{yr}^{-1}( \pm 1$ s.e. of the slope $)$ and for $1992-2006, \mathrm{~d}(\mathrm{DTR}) / \mathrm{d} t=-0.045 \pm 0.013^{\circ} \mathrm{C} \mathrm{yr}^{-1}$. As expected, decreasing the number of values in our sample from $n=30$ to $n=15$, corresponds to an increase of the s.e. of the slope. However, both $\mathrm{d}(\mathrm{DTR}) / \mathrm{d} t$ values are in reasonably good agreement with the 30-yr trend given above $\left(\mathrm{d}(\mathrm{DTR}) / \mathrm{d} t=-0.050 \pm 0.007^{\circ} \mathrm{C} \mathrm{yr}^{-1}\right)$.

In the DTR analyses above, the annual means, $T_{\max }, T_{\min }$ and DTR, are based on the means of daily minimum and maximum hourly temperatures obtained from calendar days ( $h=01: 00$ to 24:00 LST). However, in doing so, there is the possibility that an hourly minimum temperature for two successive calendar days might be from the same evening (e.g. one value is at 23:00 LST, the other at 01:00 LST). To reduce the possibility of two successive daily minimum temperatures being chosen from the "same" evening, one can also consider an observational day (vs. a calendar day), where the $24 \mathrm{~h}$ period considered begins in the morning (e.g. 08:00 LST) or evening (e.g. 19:00 LST). A detailed discussion of the influence of different $24 \mathrm{~h}$ periods chosen on daily minimum and maximum temperatures is given by Janis (2002). The analyses done in this section are therefore repeated, but using an observational day from $h=08: 00$ LST (of a given day) to 07:00 LST (on the next day). We find that the percent difference between individual annual mean values using calendar days (i.e. the diamonds, triangles and squares given in Fig. 5a and b) and observation days (be- ginning at 08:00 LST), to be $0.0-0.2 \%$ for $T_{\max }, 1.3-5.6 \%$ for $T_{\min }$, and $0.5-1.8 \%$ for DTR. The resultant changes to the overall trends given in Fig. 5a and b were also considered, and found to be very small, with percent changes to the slope values given in Fig. 5a and b less than $1 \%\left(\mathrm{~d} T_{\max } / \mathrm{d} t\right.$ by $0.9 \%, \mathrm{~d} T_{\min } / \mathrm{d} t$ by $0.0 \%$, and $\mathrm{d}(\mathrm{DTR}) / \mathrm{d} t$ by $\left.0.2 \%\right)$. We therefore conclude that the choice of $24 \mathrm{~h}$ period, when determining annual means for $T_{\max }, T_{\min }$ and DTR, has little effect on the overall trends shown in Fig. 5a and b, and continue to use calendar days for our analyses.

We compare our DTR results with those of other studies (Table 1), ranging from analyses done on one single station to 7000 spatially averaged stations. Grant et al. (2005) obtained an annual DTR change $\left(\approx-0.0020^{\circ} \mathrm{C} \mathrm{yr}^{-1}, 1935\right.$ 2003) for a high-altitude station at Mt Washington that is approximately an order of magnitude smaller than our Hawaii results $\left(\approx-0.050^{\circ} \mathrm{C} \mathrm{yr}^{-1}, 1977-2006\right)$. Although both sites are high altitude, Mt Washington is influenced by a continental location and is closer to anthropogenic influences than the Mauna Loa Observatory. There are also differences in local winds, cloud cover, synoptic systems, and the period studied is twice as long. Giambelluca et al. (2008) studied records from 21 stations on Hawaii. They spatially averaged four high-altitude stations ( $>900 \mathrm{~m}$ a.s.l.) over the period 19752006 and found an annual DTR change $\approx-0.036^{\circ} \mathrm{C} \mathrm{yr}^{-1}$, slightly less than the value we obtain. Vose et al. (2005) obtained maximum temperatures, minimum temperatures and DTR trends globally for the period 1979-2004, approximately the same period we consider. With maximum temperature data averaged over 7018 stations and minimum temperature and DTR data averaged over 6970 stations, they found $\mathrm{d} T_{\max } / \mathrm{d} t \approx 0.0287^{\circ} \mathrm{C} \mathrm{yr}^{-1}, \mathrm{~d} T_{\min } / \mathrm{d} t \approx 0.0295^{\circ} \mathrm{C} \mathrm{yr}^{-1}$, and an annual DTR change $\approx-0.0001^{\circ} \mathrm{C} \mathrm{yr}^{-1}$. Differences with our analysis in Hawaii are expected since most stations in the Vose et al. (2005) global study are continental and at low elevations.

The seasonal variability of $\mathrm{d} T_{\max } / \mathrm{d} t, \quad \mathrm{~d} T_{\min } / \mathrm{d} t$ and $\mathrm{d}(\mathrm{DTR}) / \mathrm{d} t$, is assessed for summer months (June, July, August) and winter months (December, January, February) for the 30-yr time period (Fig. 6). Also included are the annual 


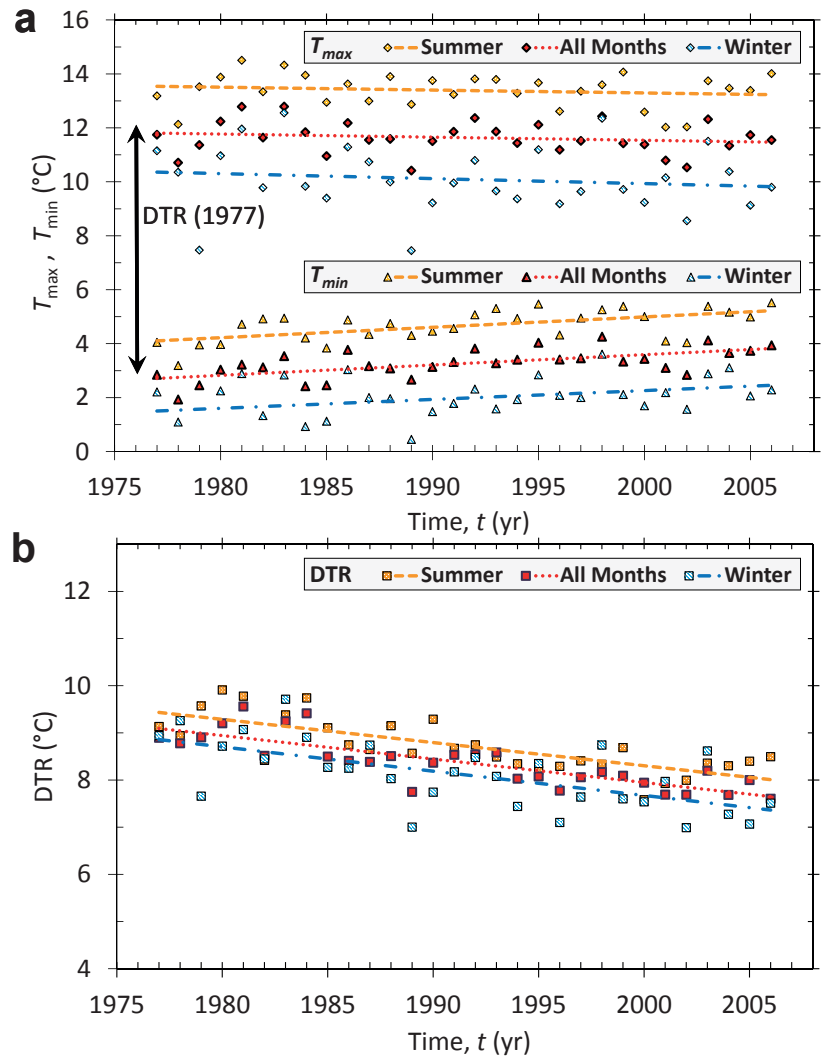

Fig. 6. Annual mean maximum temperatures $\left(T_{\max }\right)$, minimum temperatures $\left(T_{\min }\right)$, and diurnal temperature ranges (DTR), for 1977-2006, based on hourly Mauna Loa Observatory, Hawaii data (NOAA, 2009), given for "all months" during the year, summer (June, July, August) and winter (December, January, February). (a) The sequence of annual mean maximum temperatures $T_{\max }$ (diamonds) and minimum temperatures $T_{\min }$ (triangles) are given as a function of time $t$ for 1977-2006, for all months considered together (dark red diamonds/triangles, same as Fig. 5a), summer (yellow diamonds/triangles) and winter (blue diamonds/triangles). An illustration of DTR $=T_{\max }-T_{\min }$ for 1977 is also shown (vertical arrow). (b) The annual mean values of DTR are given as a function of time $t$, for all months considered together (red squares, same as Fig. 5b), summer (triangles) and winter (circles). Also shown in (a) and (b) are best-fit linear trends of the annual values (dashed lines: summer; dotted lines: all months; dash-dotted lines: winter). The slopes for each line in (a) and (b) ( \pm 1 s.e. of the slope) are summarized in Table 2, along with those from equivalent analyses for fall and spring.

mean values ("all months") from Fig. 5. In each case the best-fit line (using ordinary least-squares) to the data is also shown, with the resultant slopes summarized in Table 2, along with those for spring (March, April, May) and fall (September, October, November). From Table 2, it is seen that there is some seasonal variability for $\mathrm{d} T_{\max } / \mathrm{d} t$ and $\mathrm{d} T_{\min } / \mathrm{d} t$ trends, but very little variability in $\mathrm{d}(\mathrm{DTR}) / \mathrm{d} t$. The lack of seasonal variability in $\mathrm{d}(\mathrm{DTR}) / \mathrm{d} t$ suggests a minimal role of local and regional influences (e.g. cloud cover,
Table 2. Best-fit annual mean trend line slopes, $\mathrm{d} T_{\max } / \mathrm{d} t, \mathrm{~d} T_{\min } / \mathrm{d} t$, and $\mathrm{d}(\mathrm{DTR}) / \mathrm{d} t$, based on hourly temperature data (NOAA, 2009) from the Mauna Loa Observatory, Hawaii, 1977-2006, given for four seasons (spring, summer, fall, winter) and all months. Trend lines for summer, winter and all months are given in Fig. 6. Uncertainties are \pm 1 s.e. of the slope.

\begin{tabular}{lccc}
\hline Time Period & $\begin{array}{c}\mathrm{d} T_{\max } / \mathrm{d} t \\
\left({ }^{\circ} \mathrm{C} \mathrm{yr}^{-1}\right)\end{array}$ & $\begin{array}{c}\mathrm{d} T_{\min } / \mathrm{d} t \\
\left({ }^{\circ} \mathrm{C} \mathrm{yr}^{-1}\right)\end{array}$ & $\begin{array}{c}\mathrm{d}(\mathrm{DTR}) / \mathrm{d} t \\
\left({ }^{\circ} \mathrm{C} \mathrm{yr}^{-1}\right)\end{array}$ \\
\hline Spring & $-0.003 \pm 0.022$ & $0.047 \pm 0.013$ & $-0.050 \pm 0.013$ \\
Summer & $-0.011 \pm 0.014$ & $0.038 \pm 0.010$ & $-0.049 \pm 0.008$ \\
Fall & $-0.018 \pm 0.013$ & $0.032 \pm 0.009$ & $-0.050 \pm 0.009$ \\
Winter & $-0.019 \pm 0.026$ & $0.033 \pm 0.016$ & $-0.052 \pm 0.012$ \\
\hline All months & $-0.011 \pm 0.013$ & $0.038 \pm 0.009$ & $-0.050 \pm 0.007$ \\
\hline
\end{tabular}

* Spring (March, April, May); summer (June, July, August); fall (September, October, November); winter (December, January, February)

winds, synoptic systems), and does not reject the hypothesis that the decrease in DTR may be associated with the increase in global anthropogenic $\mathrm{CO}_{2}$.

We now address how changes over the period 1977-2006 in atmospheric $\mathrm{CO}_{2}$ relate to changes in Mauna Loa annual mean temperature $(T)$, annual mean maximum $\left(T_{\max }\right)$ and minimum $\left(T_{\min }\right)$ temperature (Fig. 5), and annual mean DTR (Fig. 5). Based on Eq. (3) we show (Fig. 7) the dependence of these annual mean variables as a function of $5.35 \ln \left(C / C_{0}\right)$, where $C$ is the annual mean concentration of $\mathrm{CO}_{2}$ and $C_{0}=334 \mathrm{ppmv}$ is for 1977 (CDIAC, 2009). For each case, the best-fit line (using ordinary least-squares) is shown, along with its slope, which from Eq. (3) is the value of the equilibrium climate sensitivity $\lambda$. However, we recognise that this proportionality is directly applicable only to $T$, the annual mean temperature, i.e. the temperature averaged over the $24 \mathrm{~h}$ calendar day (and all days of the year). We obtain $\lambda[T]=0.84 \pm 0.45^{\circ} \mathrm{C} \mathrm{m}^{2} \mathrm{~W}^{-1}$ ( \pm 1 s.e. of the slope), $\lambda\left[T_{\max }\right]=-0.48 \pm 0.53^{\circ} \mathrm{C} \mathrm{m}^{2} \mathrm{~W}^{-1}$, $\lambda\left[T_{\text {min }}\right]=1.58 \pm 0.38^{\circ} \mathrm{C} \mathrm{m}^{2} \mathrm{~W}^{-1}, \quad$ and $\lambda[\mathrm{DTR}]=-2.06 \pm$ $0.28^{\circ} \mathrm{C} \mathrm{m}^{2} \mathrm{~W}^{-1}$. As previously noted in Sect. 3, our value $\lambda[T]=0.84 \pm 0.45^{\circ} \mathrm{C} \mathrm{m}^{2} \mathrm{~W}^{-1}$ is in quiet good agreement with preferred global values (Gregory et al., 2002; IPCC, 2007) of $\lambda=0.8[0.5$ to 1.2$]{ }^{\circ} \mathrm{C} \mathrm{m}^{2} \mathrm{~W}^{-1}$. The other three slopes, $\lambda\left[T_{\max }\right], \lambda\left[T_{\min }\right], \lambda[\mathrm{DTR}]$, can be taken as proxies for the relation between $\mathrm{CO}_{2}$ and the respective variables $T_{\max }$, $T_{\min }$, and DTR. These three values of $\lambda$ once again emphasize the difference between day-time temperature, night-time temperature and DTR trends. Based on these values, we hypothesize that the influence of $\mathrm{CO}_{2}$ increase is primarily a night-time effect. 


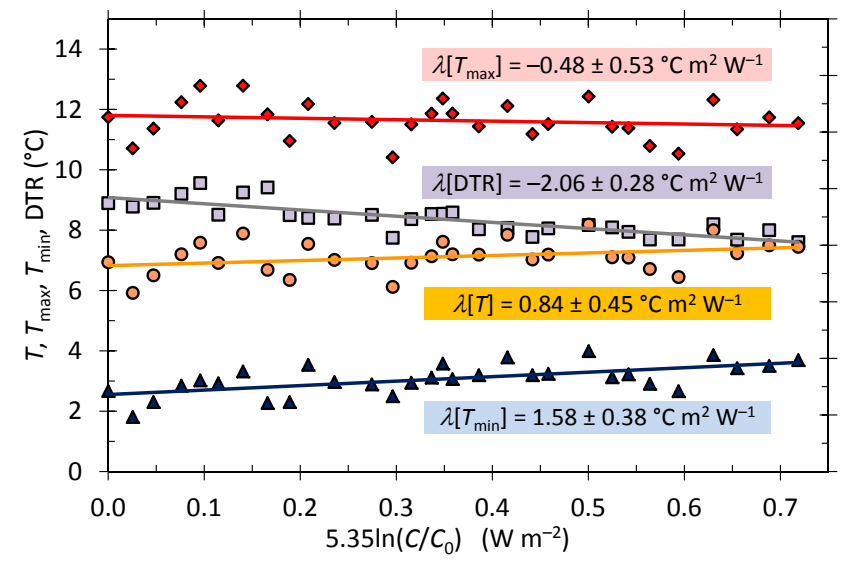

Fig. 7. Annual mean temperatures ( $T$, circles), maximum temperatures $\left(T_{\max }\right.$, diamonds), minimum temperatures $\left(T_{\min }\right.$, triangles), and diurnal temperature ranges (DTR, squares), calculated for each year 1977-2006, based on the hourly Mauna Loa Observatory, Hawaii temperature data (NOAA, 2009), given as a function of $5.35 \ln \left(C / C_{0}\right)$ (see Eq. 3), where $C$ (CDIAC, 2009) is the annual mean concentration of $\mathrm{CO}_{2}$ and $C_{0}=334 \mathrm{ppmv}$ is the reference value for 1977. Also shown for each temperature variable is the ordinary least-squares best-fit line along with its slope $\lambda( \pm 1$ s.e. of the slope), which is the equilibrium climate sensitivity $\lambda$ from Eq. (3).

\section{Discussion}

The systematic increase in atmospheric $\mathrm{CO}_{2}$ has been convincingly demonstrated by measurements made at the Mauna Loa Observatory (Keeling et al., 1976), where the temporal change of annual mean values of $\mathrm{CO}_{2}$ concentrations 1977-2006 is well represented by a linear trend

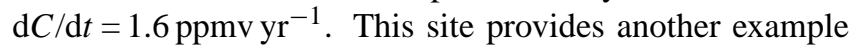
of an area with minimally-varying site characteristics, such as found in (often old) cities (Parker, 2006, 2010; Jones and Lister, 2009), which have been used to detect regional to global warming trends. The micro-scale temporal consistency of the surroundings of the site, allows detection of macro-scale (i.e. regional to global) warming trends. One focus of this paper has been to consider the potential implications of the Mauna Loa temperature trends as a proxy for global effects.

As discussed above, we have found (Fig. 2b) that there is an overall annual warming trend of temperatures $\mathrm{d} T / \mathrm{d} t=0.021 \pm 0.011^{\circ} \mathrm{C} \mathrm{yr}^{-1}$ at this observatory for the same period. This is very close to the Hawaii regional sea surface temperature (SST) trend $\mathrm{d}(\mathrm{SST}) / \mathrm{d} t=0.018$ $\pm 0.006{ }^{\circ} \mathrm{C} \mathrm{yr}^{-1}$ for the period $1977-2006$ (Fig. 4), the average "preferred" value of the IPCC (2007) for the period 1980-2005 of $\overline{\mathrm{d} T / \mathrm{d} t}=0.018 \pm 0.005^{\circ} \mathrm{C} \mathrm{y}^{-1}$ and our inferred $\mathrm{CO}_{2}$ trend analysis value of $\mathrm{d} T / \mathrm{d} t=0.019[0.012$ to $0.029]{ }^{\circ} \mathrm{C} \mathrm{yr}^{-1}$. We suggest that these similar trends may tentatively imply that the Mauna Loa temperatures can be associated with global variability, at least at low latitudes.
At the Mauna Loa Observatory, we find a systematic dependence of temperature change on the time of day. During the hours of darkness, there is a near-uniform annual warming during the $30-\mathrm{yr}$ period $1977-2006$ of $0.040^{\circ} \mathrm{C} \mathrm{yr}^{-1}$ (Fig. 2b). However, during the hours of sunlight there is a systematic decrease in this warming trend during the morning, showing a slight cooling of $-0.014^{\circ} \mathrm{C} \mathrm{yr}^{-1}$ at 12:00 LST (noon), and then a systematic increase in the afternoon (Fig. 2b). Over the 30-yr period, this dominance of nighttime warming results in a relatively large annual decrease in the diurnal temperature range (DTR) of $-0.050^{\circ} \mathrm{C} \mathrm{yr}^{-1}$ (Fig. 5b).

Newman et al. (2010) have studied the record breaking statistics of the daily maximum and minimum temperatures in the same 30-yr Mauna Loa, Hawaii data that we use here (for 1977-2006). They consider maximum and minimum temperatures on a daily basis. For the minimum temperatures, they find an excess of the number of record setting high temperatures compared to the number of record setting low temperatures, while for maximum temperatures the numbers of record setting high temperatures and record setting low temperatures are approximately equal. These results are consistent with the moderate night-time warming and small day-time cooling reported here.

In this paper we have discussed the observed temperature trends at Mauna Loa in the context of global changes in $\mathrm{CO}_{2}$. There are other potential causes for these temperature trends, including local changes in wind velocity and cloud cover, and variations in the occurrences and intensity of regional synoptic systems. However, because of feedbacks, it is hard to separate cause from effect. For example, we would expect changes in temperature to impact and be impacted by cloud cover, wind, etc., on the micro-scale and indeed all scales. Doing a definitive study to separate cause and effect would require significant physically-based modelling, which is outside of this study. A principal focus of this paper has been the systematic downward trend in DTR. Environmental and seasonal variations in DTR have been discussed by several authors (e.g. Leathers et al., 1998; Scheitlin and Dixon, 2010). As shown in Fig. 6b, there is very little seasonal influence on the DTR trends at Mauna Loa.

Our basic hypothesis is that a large part of the temperature and DTR trends at Mauna Loa can be attributed to changes in $\mathrm{CO}_{2}$. At night, longwave radiation and turbulent sensible heat fluxes dominate heat loss. Increasing presence of green house gases will result in enhanced reradiation back towards the surface and hence warming nocturnal temperatures. During the day time, shortwave radiation dominates, particularly in tropical regions. It would be expected that the role of green house gases would be greater in the early morning before significant heating enhances boundary layer depth. At the end of the day, the boundary layer collapses. A possible explanation for the middle of the day cooling is that the enhanced surface heating is actually resulting in greater mixing and therefore a decrease in the near-surface green house gas 
concentration which would reduce incoming longwave radiation. These trends are consistent with the observed increases in the concentrations of $\mathrm{CO}_{2}$ and its role as a greenhouse gas, and indicate the possible relevance of the Mauna Loa temperature measurements to global warming.

Reference temperatures over specific 30-yr periods are referred to as temperature normals. We suggest that the hourly temperature trends given in Fig. 2b, and the DTR trend given in Fig. 5b, for the 30-yr period at Mauna Loa, could be considered temperature trend and DTR trend normals, potentially representative of global values. Based on our results, we suggest that both temperature and DTR trends should be a part of studies of global warming. Specifically global climate model studies of global change should yield changes in DTR consistent with observations.

Acknowledgements. We thank two anonymous reviewers for their very useful and extensive comments and suggestions.

Edited by: V. Rath

\section{References}

CDIAC - Carbon Dioxide Inf. Anal. Cent.: Oak Ridge Natl. Lab., Oak Ridge, Tenn, Atmospheric $\mathrm{CO}_{2}$ concentrations (ppmv) derived from in situ air samples collected at Mauna Loa Observatory, Hawaii, updated 2005, http://cdiac.ornl.gov/trends/co2/ maunaloa.co2, last access: 1 December 2009.

Fujibe, F.: Detection of urban warming in recent temperature trends in Japan, Int. J. Climatol., 29, 1811-1822, 2009.

Giambelluca, T. W., Diaz, H. F., and Luke, M. S. A.: Secular temperature change in Hawai'i, Geophys. Res. Lett., 35, L12702, doi:10.1029/2008GL034377, 2008.

Grant, A. N., Pszenny, A. A. P., and Fischer, E. V.: The 1935-2003 air temperature record from the summit of Mount Washington, New Hampshire, J. Climate, 18, 4445-4453, 2005.

Gregory, J. M., Stouffer, R. J., Raper, S. C. B., Stott, P. A., and Rayner, N. A.: An observationally based estimate of the climate sensitivity, J. Climate, 15, 3117-3121, 2002.

IPCC: Summary for Policymakers, in: Climate Change 2007: The Physical Science Basis. Contribution of Working Group I to the Fourth Assessment Report of the Intergovernmental Panel on Climate Change, edited by: Solomon, S. D., Qin, D., Manning, M., Chen, Z., Marquis, M., Averyt, K. B., Tignor, M., and Miller, H. L., Cambridge University Press, Cambridge, UK and New York, NY, USA, 2007.

Janis, M. J.: Observation-time-dependent biases and departures for daily minimum and maximum air temperatures, J. Appl. Meteorol., 42, 588-603, 2002.

Jones, P. D. and Lister, D. H.: The Urban Heat Island in Central London and urban-related warming trends in Central London since 1900, Weather, 64, 323-327, doi:10.1002/wea.432, 2009.
Jones, P. D. and Moberg, A.: Hemispheric and large-scale surface air temperature variations: an extensive revision and update to 2001, J. Climate, 16, 206-223, 2003.

Kalnay, E., Kanamitsu, M., Kistler, R., Collins, W., Deaven, D., Gandin, L., Iredell, M., Saha, S., White, G., Woollen, J., Zhu, Y., Leetmaa, A., Reynolds, R., Chelliah, M., Ebisuzaki, W., Higgins, W., Janowiak, J., Mo, K. C., Ropelewski, C., Wang, J., Jenne, R., and Joseph, D.: The NCEP/NCAR 40-year reanalysis project, B. Am. Meteorol. Soc., 77, 437-471, doi:10.1175/15200477(1996)077<0437:TNYRP>2.0.CO;2, 1996.

Keeling, C. D., Bacastow, R. B., Bainbridge, A. E., Ekdahl, C. A., Guenther, P. R., Waterman, L. S., and Chin, J. F. S.: Atmospheric carbon dioxide variations at Mauna Loa Observatory, Hawaii, Tellus, 28, 538-551, 1976.

Leathers, D. J., Palecki, M. A., Robinson, D. A., and Dewey, K. F.: Climatology of the daily temperature range annual cycle in the United States, Clim. Res., 9, 197-211, 1998.

Myhre, G., Highwood, E. J., Shine, K. P., and Stordal, F.: New estimates of radiative forcing due to well mixed greenhouse gases, Geophys. Res. Lett., 25, 2715-2718, 1998.

Newman, W. I., Malamud, B. D., and Turcotte, D. L.: Statistical properties of record-breaking temperatures, Phys. Rev. E, 82, 066111, doi:10.1103/PhysRevE.82.066111, 2010.

NOAA (National Oceanic and Atmospheric Administration): Earth System Research Laboratory (ESRL), Mauna Loa hourly temperature data for 1 January 1997 to 7 February 2007, updated 2008, ftp://ftp.cmdl.noaa.gov/met/hourlymet, last access: 1 December 2009.

NOAA (National Oceanic and Atmospheric Administration): Earth System Research Laboratory (ESRL), SST RNCEP/NCAR Reanalysis monthly means of SST, updated November 2010, http: //www.esrl.noaa.gov/psd/data/timeseries/, last access: $15 \mathrm{De}-$ cember 2010.

Parker, D. E.: A demonstration that large-scale warming is not urban, J. Climate, 19, 2882-2895, doi:10.1175/JCLI3730.1, 2006.

Parker, D. E.: Urban heat island effects on estimates of observed climate change, WIREs, Climatic Change, 1, 123-133, doi:10.1002/wcc.21, 2010.

Ryan, S.: Estimating volcanic $\mathrm{CO}_{2}$ emission rates from atmospheric measurements on the slope of Mauna Loa, Chem. Geol., 177, 201-211, 2001.

Scheitlin, K. N. and Dixon, P. G.: Diurnal temperature range variability due to land cover and airmass types in the Southeast, J. Appl. Meteorol., 49, 879-888, doi:10.1175/2009JAMC2322.1, 2010.

Vose, R. S., Easterling, D. R., and Gleason, B.: Maximum and minimum temperature trends for the globe: an update through 2004, Geophys. Res. Lett., 32, L23822, doi:10.1029/2005GL024379, 2005. 